\title{
Study on different types of defects and their causes and remedies in garments industry
}

\begin{abstract}
Now a days Garments defect is one of the most important factors of the apparel manufacturing industry because it creates a negative effect on actual productivity. This paper aims with Different types of Defects which are the common term in the garment industry. In this research we have found that it is very essential to know about different types of Garments Defects. In garments industry these defects are dependent upon the classification of defects and an inspector's ability to make decisions. If there is no idea of garments defects identification then it will be a tough job, but if it is known properly then it is an easy task to identify defects. So must know all types of Garments defects if we are involved with the apparel industry. It is the responsibility of the garments manufacturers to maintain a required Garments quality standard for each and every product they are offering or delivering to the buyers. After reading this project we have found that the idea about all types of garments defects like fabric defects, cutting \& spreading defects, sewing defects and finishing defects.
\end{abstract}

Keywords: garments defects, defects name, defects causes, defects remedies, fabric defects, cutting \& spreading defects, sewing defects, finishing defects
Volume 5 Issue 6 - 2019

\author{
Mafzal Ahmed, ' Tarikul Islam, ${ }^{2}$ Md Sujan Ali ${ }^{3}$ \\ 'Department of Textile Engineering, Port City International \\ University, Bangladesh \\ ${ }^{2}$ Department of Textile Engineering, Jashore University of \\ Science and Technology, Bangladesh \\ ${ }^{3}$ Department of Textile Engineering, Mawlana Bhashani Science \\ and Technology University, Bangladesh
}

\begin{abstract}
Correspondence: Dr. Mafzal Ahmed, Professor, Departmen of Textile Engineering, Port City International University, Chittagong-4225, Bangladesh, Tel +880 I 7 I 4289982, Emailmafzalahmed5@gmail.com
\end{abstract}

Received: November 05, 2019 | Published: November 28, 2019

\section{Introduction}

In present the ready-made Garments is one of the parts of parcel of Garments sector. On the other hand the ready-made garment is totally incomplete without sewing process. But it is true that, sometimes we do not get the expected result in this section. ${ }^{1}$ It is because of lack of proper skill, machine disturbance and improper machine adjustment. Due to these obscurities fault occurred and effects quality, productivity, expense and also efficiency. So Quality standards are part of a firm standard operating procedure, product development and production planning. Standards reflect the overall intrinsic quality level the firm seeks to achieve. ${ }^{2}$ The fundamental purpose of using quality standard is to provide consistency between products and products line. ${ }^{3}$

Defect in the garments industry is a common phenomenon that hampers the smooth production rate and focus on poor quality products having an impact on overall factory economy. Minimization of defects is a must in quality and productivity improvement. Rework is a vital issue for poor quality product and low production rate. ${ }^{4}$ Reworks are the nonproductive activities focusing on any activity that customers are not willing to pay for. Non productive activities describe that the customers does not consider as adding value to his product. By reacting quicker in minimization of reworks to make a product as per customer demand with expected quality, the company can invest less money and more costs savings. ${ }^{5,6}$

Because of maintaining standard or quality of product it is mandatory to detect the fault and find out the best solution to diminish the error. ${ }^{4}$ Among the process control list, product control chart was used in the study. "Defect Detection", has the objective of identifying defect cause and impending real-time means of uncovering of faults. ${ }^{7}$

The defect of sewing section has a great relationship between quality and productivity. If more defects are found after sewing, then negative impact on costs of the product. ${ }^{8}$ There is different plus to identifying an imperfection before other operations hinder seam removal and re sewing. This observation is based upon the current system in which the operator serves as the first line of quality control implementation. And other sewing stations have no operator to serve in the first line quality control position. Then finally assessment procedure of defect was done and find out the best suggestion. ${ }^{9}$

Controlling defects is the key factor for garments quality control. As mentioned in this article, these 6 areas have quality checkpoints to find out all types of defects found in the apparel industry. ${ }^{10}$ Cutting, sewing, washing and finishing all section have specific defect which effect on whole garments quality. So it is clear that if we don't control these defects in every section we will not able to much profit. Here we will discuss and give a list of every section wise defects to understand easily. And we will also show the causes of the defects and what their remedies.

The main object of this project is to minimize these defects. That's why the production is increased because without minimize the defects it is not possible to increase productivity. So our aim is to promote indigenous manufacturing of high quality trims and accessories and to produce defect free garments.

\section{Materials and methods}

\section{Materials}

a. Fabric inspection machine

b. Cutting machine

c. Sewing machine

d. Inspection table

e. Light source

f. Paper

g. Pencil

h. Hard board

i. Calculator etc. 


\section{Methods}

Different types of defects which are found in garments industry and their remedies.

\section{Seam Puckering}

Seam puckering refers to the gathering of a seam either just after sewing or after laundering causing an unacceptable seam appearance (Figure 1).

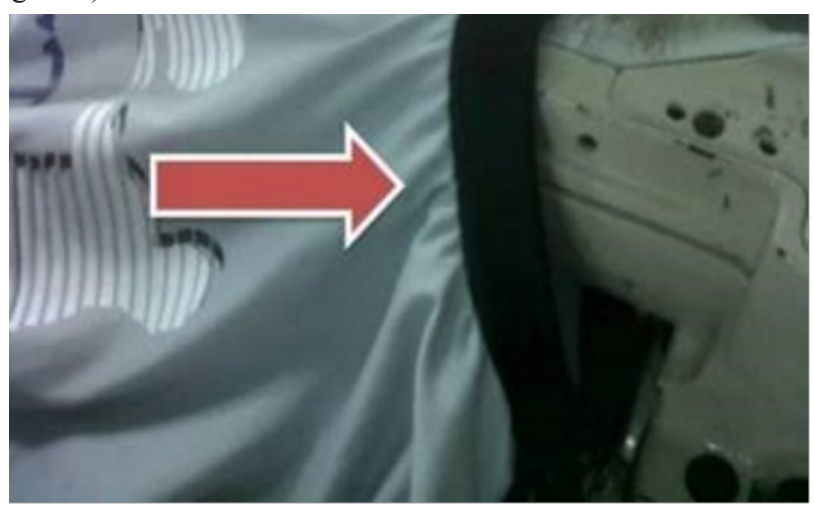

Figure I Seam puckering."

\section{Causes:}

1. Uneven stretching on to plies of fabric during sewing.

2. Improper thread tension.

\section{Remedies:}

1. Feed dog, eyelets and thread guides should be checked periodically for damages

2. Machine feed mechanism must be better quality.

3. Tension, SPI and presser foot pressure should not be fiddled with.

\section{Open seam or broken seam}

Portion of the garment that has not been covered by sewing thread (Figure 2).

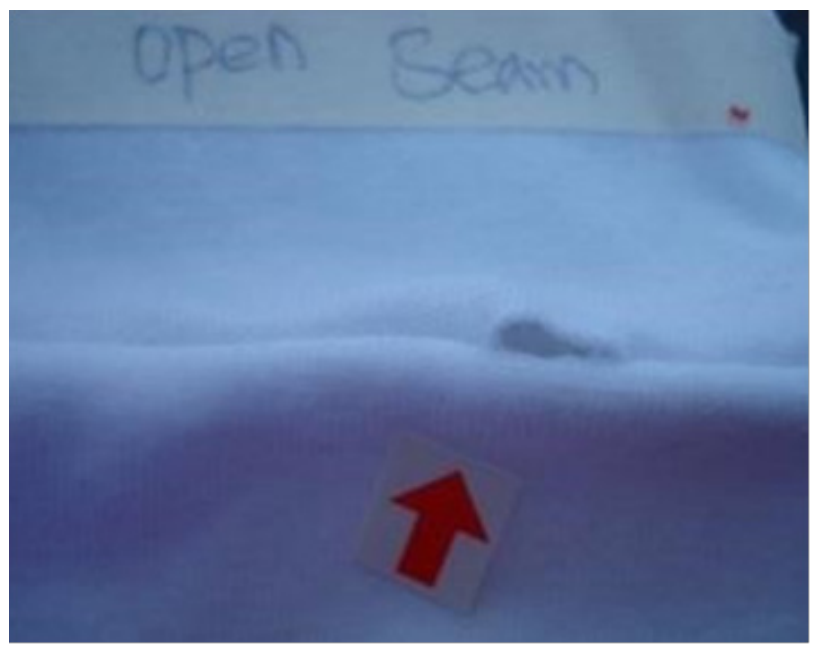

Figure 2 Open Seam in garment."

\section{Causes:}

1. Improper handling of the parts of garments.

2. Improper setting and timing between needle and looper or hook etc.

\section{Remedies:}

1. Clear markings for stitch line.

2. Proper setting and timing between needle and looper or hook.

3. Tension should be quantifiable.

\section{Broken Stitch}

Non-continuous sewing thread (Figure 3).

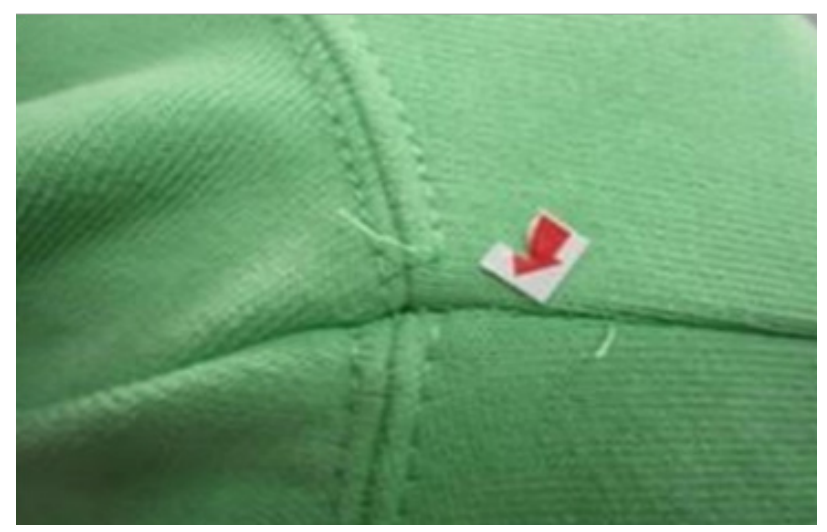

Figure 3 Broken stitches in garment."

Causes: It appears due to improper trimming or machine usage.

\section{Remedies:}

1. Needle plate, presser foot and feed dog should be checked periodically for damages.

2. Tension and threading should not be fiddled with much.

3. Proper trimming.

\section{Drop stitch/Skipped stitch}

Irregular stitching along the seam (Figure 4).

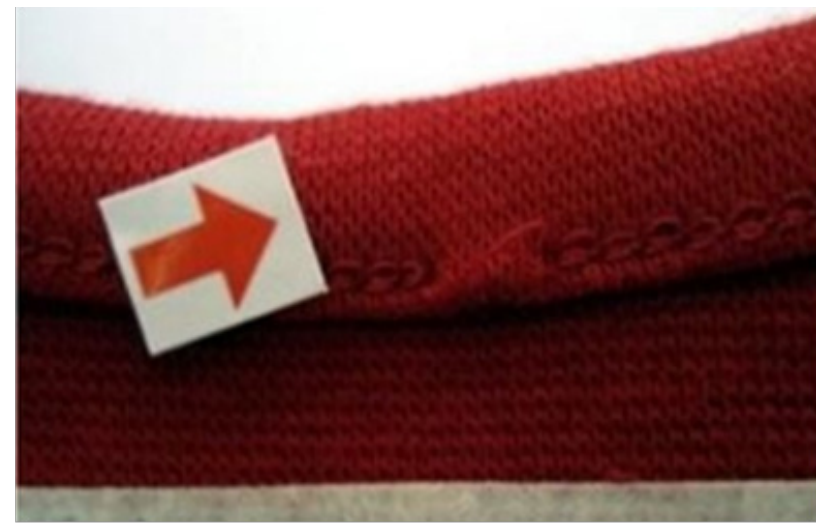

Figure 4 Drop stitch. ${ }^{12}$ 
Causes: It appears due to improper handling of cut pieces or machine usage.

\section{Remedies:}

1. Placing of needle properly.

2. Needle size \& thread size must be adjusted.

3. The pressure of pressure foot must be adjusted accurately.

\section{Uncut/ loose thread}

Extra threads or loose threads on seam line (Figure 5).

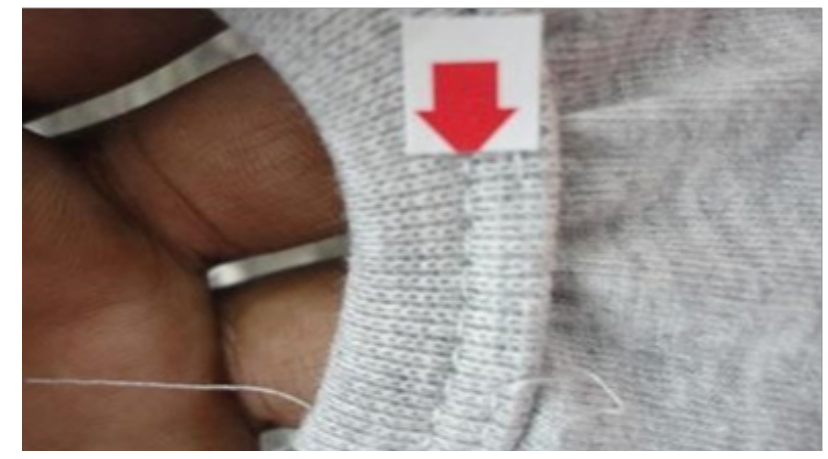

Figure 5 Loose threads on seam line. ${ }^{12}$

Causes: It appears due to improper trimming or finishing.

\section{Remedies:}

1. UBT/thread trimmer should be used

2. Operator training.

3. Garments finishing should be checked properly.

\section{Distorted knitting}

Causes: These defects can be identified by looking at the surface area; they usually appear as irregular on the fabric (Figure 6).

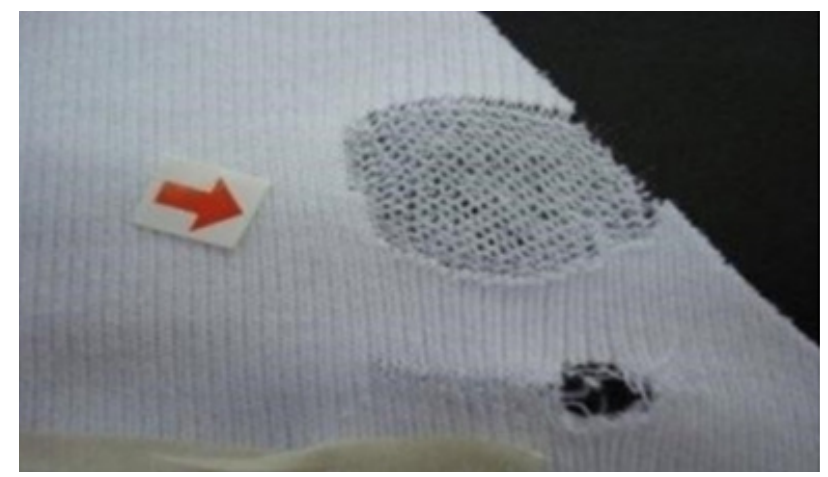

Figure 6 Distorted knitting. ${ }^{2}$

\section{Remedies:}

1. Better inspection of fabric and cut piece.

2. Ensure that fabric and cut pieces that are not up to standard are not put into line and production is wasted.

\section{Seam slippage}

Causes: This happens when the yarns in the fabric are pulled out of the seam and are more frequent in fabrics made from continuous filament yarns (Figure 7).

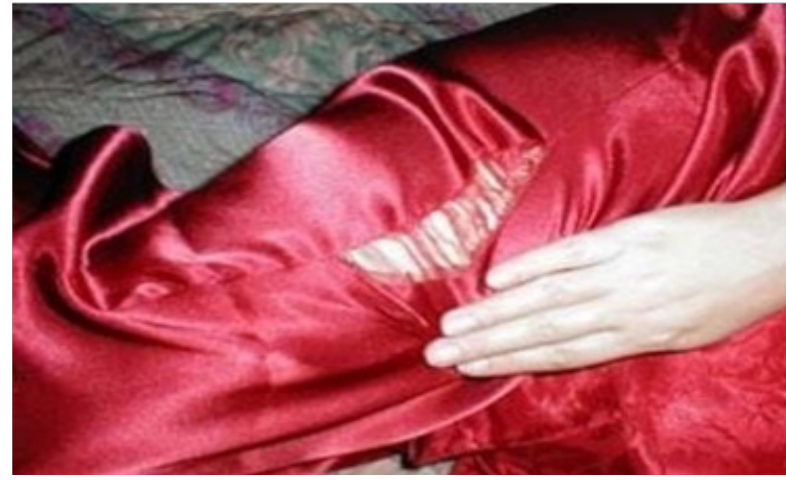

Figure 7 Seam slippage. ${ }^{12}$

\section{Remedies:}

1. French seam type can be tried.

2. Seam width can be increased.

\section{Needle threads breakage}

\section{Causes:}

1. Thread gets trapped at the thread guide.

2. Irregularities or damages in needle guard, throat plate, bobbin case and needle eye (Figure 8).

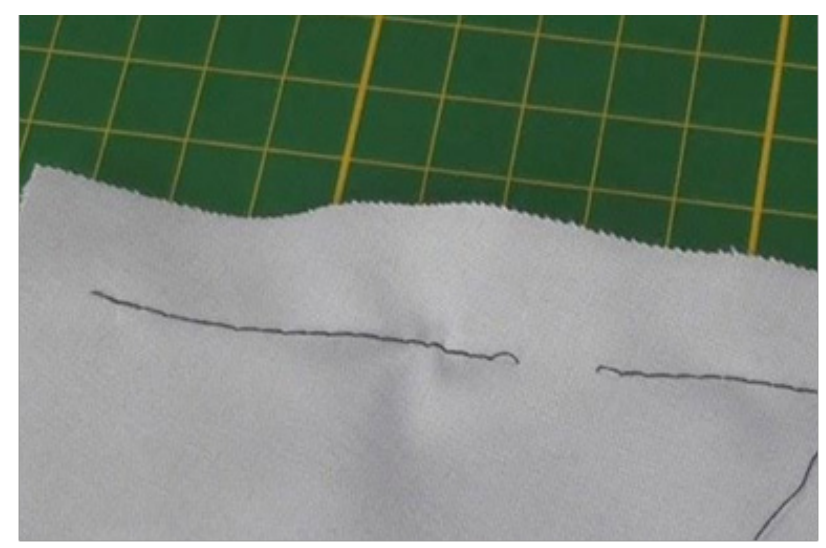

Figure 8 Needle thread breakage. ${ }^{12}$

\section{Remedies:}

1. Use a foam pad or a similar device to prevent the package from tilting.

2. Ensure that the re-threading is done correctly.

3. Replace the needle with one of better quality.

\section{Result and discussion}

\section{Analysis the cutting and spreading defects}

From Figure 9, It shows that the cutting and spreading defects percentage before rejection and after rejection. This inspection has done in JMS Garments Ltd. which is satin based woven fabric industry but here twill also be made. It is found that the defect percentage and the rejection rate was more than average $4 \%$ at the preliminary stages. And after solving the findings, the rejection percentage was less than $4 \%$ for all defects which ultimately reduced the defects and increased productivity. 


\section{Analysis the sewing defects}

From Figure 10, it illustrates different types of defect in sewing section in before and after. From our survey we can clearly say that most of the garment faults occurred in sewing section. So the sewing section is more responsible for fabric faults. To produce excellent quality of garments the sewing section must be improved.

\section{Analysis the finishing defects}

From Figure 11, It is shown that different types of defect in finishing section. And it's also shown the percentage of rejection before and after. In before the rejection rate was more but after analysis we able to decrease about $50 \%$ rejection of all defects. That plays a vital role to improve productivity.

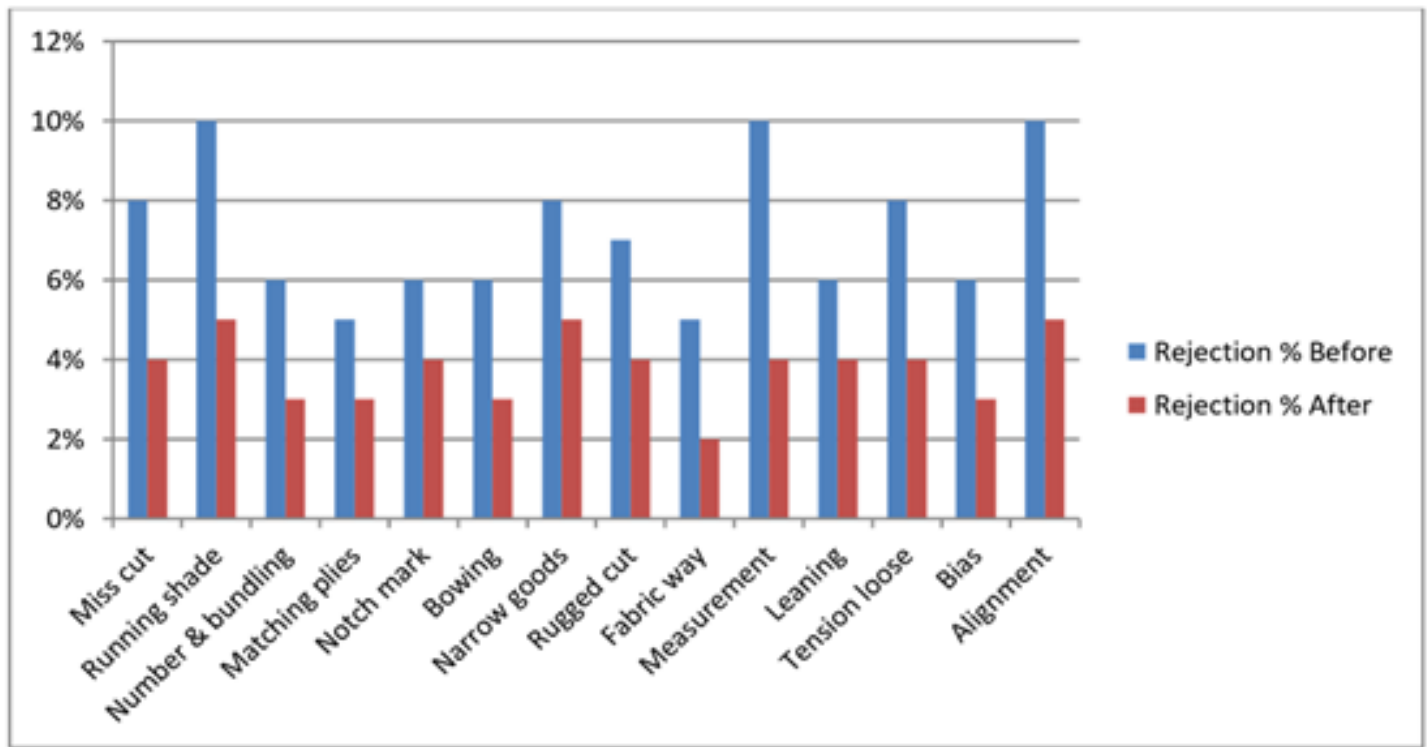

Figure 9 Cutting and spreading defects.

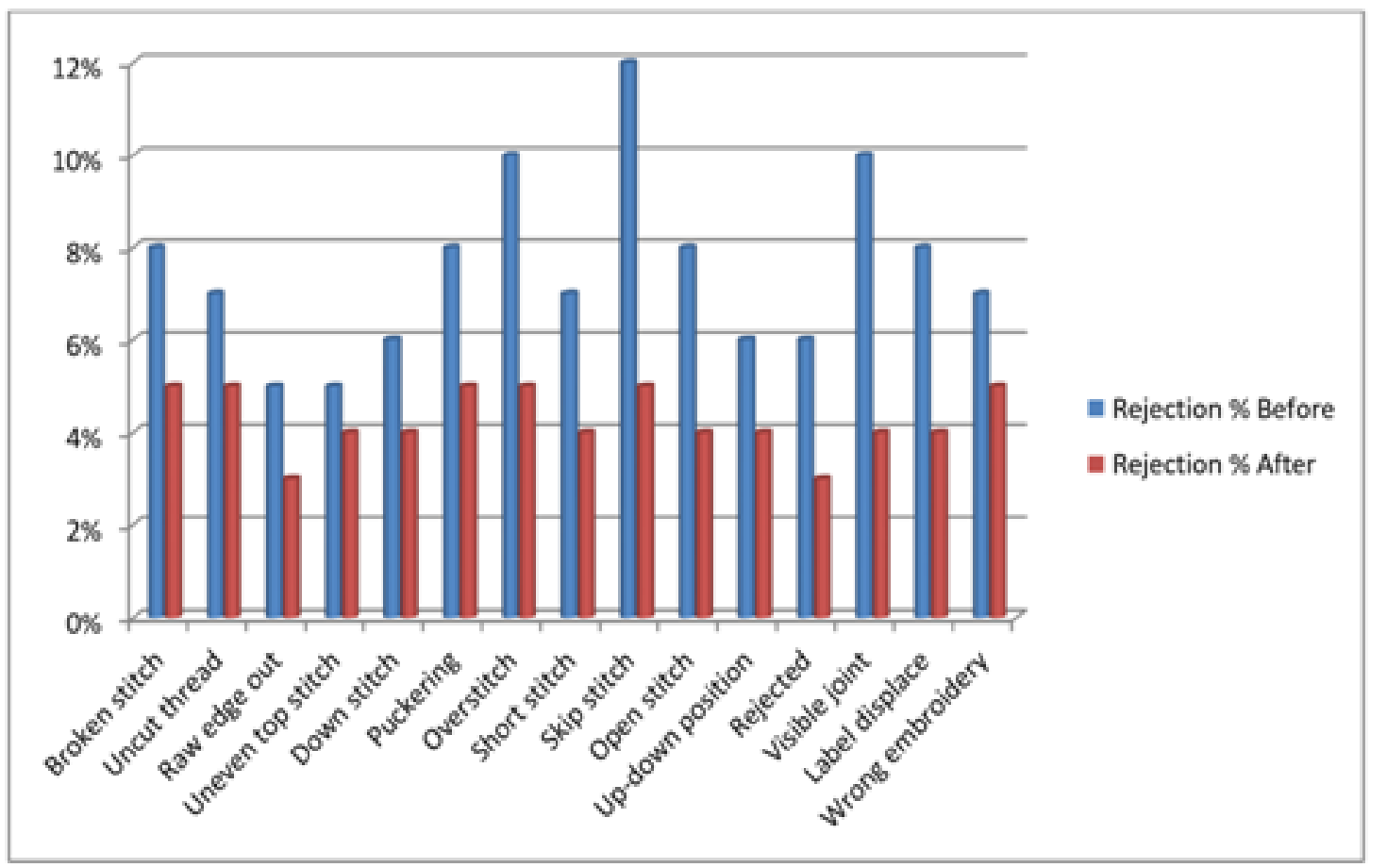

Figure 10 Sewing defects. 


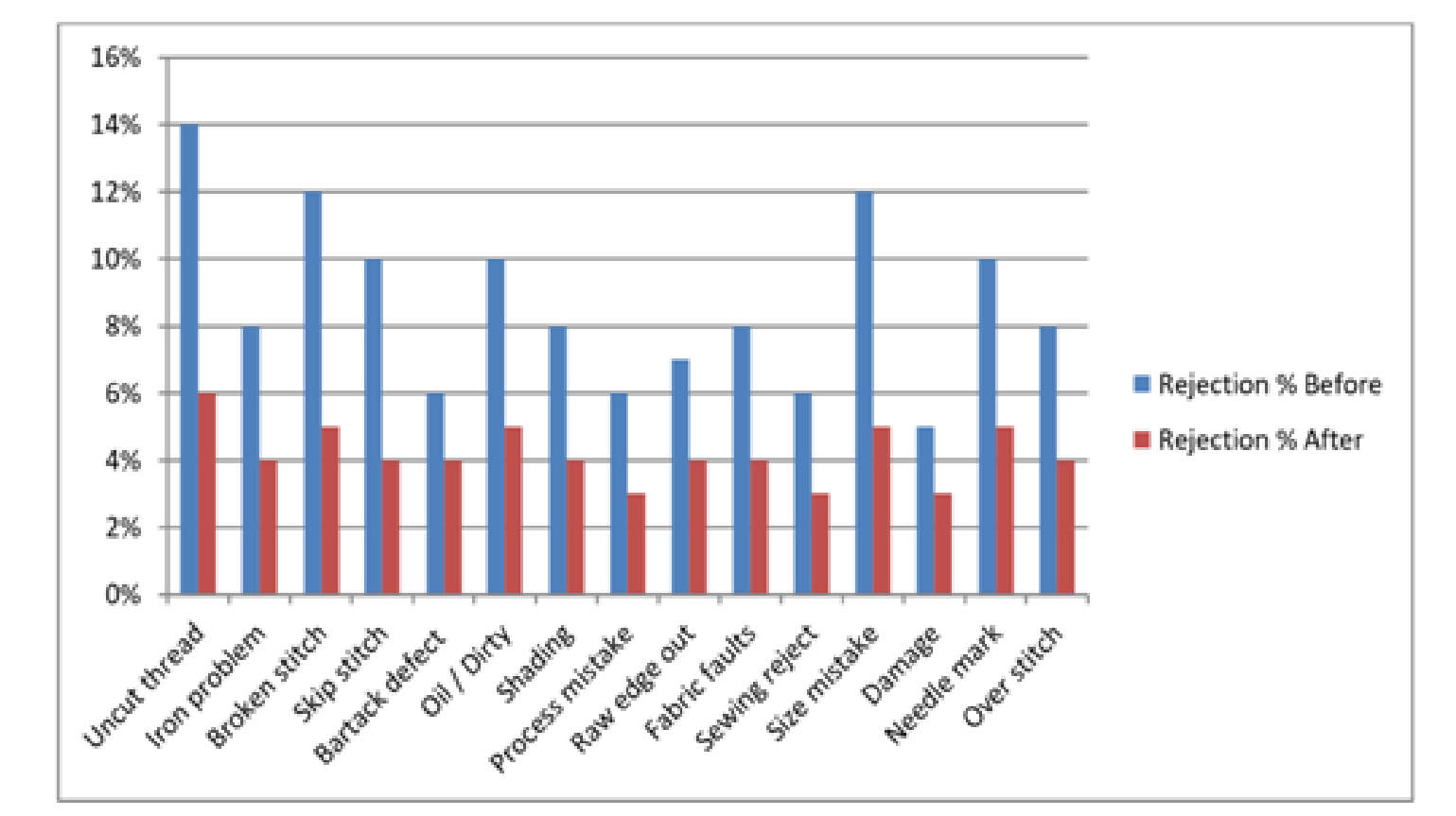

Figure II Finishing defects.

\section{Conclusion}

At last we have completed our thesis after a long time and lots of inspection, experiment $\&$ discussion. From this project, we have gathered a large experience. We have also increased our knowledge and learn how to Garments process is done, defects of Garments \& how those problems are minimized. That's why it has to be sold at lower prices, which creates a huge value loss to the company. To minimize the value loss due to variety of defects occurring in the fabric, a manufacturer should try to minimize fabric defect from every processing steps. An automated defect detection and identification system can enhance the product quality and results in improved productivity to meet both customer demands and to reduce the costs associated with off quality.

From our project work, we can say that, all the processing steps from cutting and spreading to finishing are responsible for different kinds of fabric defects. We have done project work is very careful with successfully. We found in the industry every person is very helpful and positive attitude. Finally, we can recommend that this project will be very helpful in our job life.

\section{Acknowledgments}

None.

\section{Funding}

None.

\section{Conflicts of interest}

The authors declare that they have no competing interests.

\section{References}

1. Jadhav SS, Sharma GS, Daberao AM, et al. Improve productivity in garments industry with time study. International Journal on Textile Engineering and Processes. 2017;3(4):1-6.

2. Rahman M, Baral LM, Chodhury AM, et al. Quality management in garments industry of Bangladesh. Journal of Management of sustainable Development. 2009;1:29-35.

3. Hashi MR. Different types of defects identification and controlling method for quality and productivity improvement. IOSR Journal of Polymer and Textile Engineering. 2016;3:1-18.

4. Uddin SM, Rahman CML. Minimization of defects in the sewing section of a garment factory through DMAIC methodology of six sigma. Research Journal of Engineering Sciences. 2014;3(9):21-26.

5. Islam MM, Khan MA, Khan MMR. Minimization of reworks in quality and productivity improvement in apparel industry. International Journal of Engineering and Applied Sciences. 2013;1(4):147-164.

6. Islam T, Khan SA, Sakib MH, et al. Analysis of major defects position and percentage in sewing lines of a garments factory with the help of pareto chart, cause effect diagram and sigma level. International Journal of Scientific \& Engineering Research. 2017;8(7):1885-1890.

7. Munirathinam S, Ramadoss B. Predictive models for equipment fault detection in the semiconductor manufacturing process. International Journal of Engineering and Technology. 2016;8:273-277.

8. Gopalakrishnan D, Nayak A. Defects in garments. 2008.

9. Kiron MS. Seam defects and common seam quality. 2014.

10. Karthik T, Ganesan P, Gopalakrishnan. Apparel manufacturing technology. 2018.

11. Fashion 2 Apparel. Garments defects causes and remedies. 2016.

12. Clothing Industry. Major sewing defects garments. 2018. 